Sturm und Drang 



\section{Sturm und Drang}

Geistiger Aufbruch 1770-1790 im Spiegel der Literatur

Herausgegeben von Bodo Plachta und Winfried Woesler

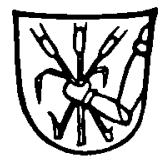

Max Niemeyer Verlag Tübingen 1997 
Die Drucklegung dieses Bandes wurde geförder durch den Landschaftsverband Osnabrück e. V.. die Stiftung der Oldenburgischen Landesbank und die Möser-Dokumentationsstelle.

Die Deutsche Bibliothek - CIP-Einheitsaufnahme

Sturm und Drang : geistiger Aufbruch 1770-1790 im Spiegel der Literatur / hrsg. von Bodo Plachta und Winfried Woesler. - Tübingen : Niemeyer, 1997

ISBN 3-484-10766-9

(C) Max Niemeyer Verlag GmbH \& Co. KG, Tübingen 1997

Das Werk einschließlich aller seiner Teile ist urheberrechtlich geschützt. Jede Verwertung außerhalb der engen Grenzen des Urheberrechtsgesetzes ist ohne Zustimmung des Verlages unzulässig und strafbar. Das gilt insbesondere für Vervielfältigungen, Übersetzungen, Mikroverfilmungen und die Einspeicherung und Verarbeitung in elektronischen Systemen. Printed in Germany.

Gedruckt auf alterungsbeständigem Papier.

Satz: Allgäuer Zeitungsverlag GmbH, Kempten

Druck: Allgäuer Zeitungsverlag GmbH, Kempten

Einband: Heinrich Koch, Tübingen 